www.jmscr.igmpublication.org

Impact Factor 5.84

Index Copernicus Value: 71.58

ISSN (e)-2347-176x ISSN (p) 2455-0450

crossref DOI: _https://dx.doi.org/10.18535/jmscr/v5i10.184

Journal Of Medical Science And Clinical Research

IGM Publication

An Official Publication of IGM Publication

\title{
Carcinosarcoma of Gallbladder with Metastases in Liver and a Lymph Node
}

\author{
Authors \\ AK Kapoor, Akanksha Singh, Pratibha Singh \\ RML Mehrotra Pathology Pvt. Ltd., Nirala Nagar, Lucknow, India \\ Corresponding Author \\ Ashok Kumar Kapoor \\ RML Mehrotra Pathology Pvt Limited, B 171, Nirala Nagar, Lucknow, India \\ Email:drashokkapoor2016@gmail.com
}

\begin{abstract}
Carcinosarcomas are highly malignant neoplasms where pleomorphic epithelial cells comingle with areas showing mesenchymal differentiation. Herewith, we describe the clinicopathological features of a case of carcinosarcoma gallbladder (CSGB). The patient was a female, aged 60 years. Immunohistochemical (IHC) examination revealed strong positivity of adenocarcinomatous tissue for cytokeratin while sarcomatous tissue showed vimentin antigen positivity. Findings of current case suggested differentiation of pluripotent tumor cells both as epithelial and mesenchymal components. She was diagnosed as a case of CSGB metastasizing in liver and a regional lymph node.

Keywords: Epithelial mesenchymal differentiation in a malignant neoplasm.
\end{abstract}

\section{Introduction}

Clinically, the patients with this tumor may present as pain in right hypochondrium. Rarely, pain may be severe and may be associated with vomiting. The patient may present as a case of acute pancreatitis. Few patients may also develop obstructive jaundice due to a stone in common bile duct. Tumor may locally invade surrounding organs, e.g. liver, stomach and transverse colon. Tumor may arise from a single pleuripotent stem cell which later differentiates into epithelial and mesenchymal cells. Herewith, we report a case of carcinosarcoma gallbladder (CSGB) with metastases both in liver and a lymph node.

\section{Case Report}

A female, aged 60 years complained of recurrent episodes of pain in right hypochondrium and vomiting for the last 1 year. She also had tenderness in right side of upper abdomen. Liver function tests revealed serum total bilirubin 0.8 $\mathrm{mg} / \mathrm{dl}$. SGPT was $60 \mathrm{U} / \mathrm{L}$ and $\mathrm{S}$. alkaline phosphatase was $120 \mathrm{U} / \mathrm{L}$. S. albumin was 3.6 $\mathrm{gm} / \mathrm{dl}$ and S. globulin was $2.4 \mathrm{gm} / \mathrm{dl}$. SGOT was 53 U/L. Later, cholecystectomy was done. Gallbladder measured $10 \times 5 \times 4 \mathrm{cms}$. It contained multiple sludge-balls. Outer surface was smooth. Cut surface of gallbladder showed an irregular tumor reaching the neck of gallbladder. Tumor measured $7 \times 3 \times 1 \mathrm{cms}$. Sections were taken both from the neck of the gallbladder and tumor tissue. 
Another piece consisted of excised wedge-shaped liver tissue, measuring $3 \times 2.5 \times 2 \mathrm{cms}$. Sections were taken. Microscopic examination showed tumor tissue. Tumor consisted of proliferated cuboidal or columnar epithelial cells forming irregular papillary structures or acini (figure 1a). Tumor cells had ovoid hyperchromatic nuclei and light-stained cytoplasm. Tumor cells showed pleomorphism. Tumor necrosis was seen. In addition, tumor showed areas of chondrosarcomatous differentiation (figure 1b). Lymphocytic infiltration and fibrosis were seen. Section from the neck of gallbladder showed structure of a lymph node showing metastatic tumor with capsular invasion (figure 1c). Section from liver also showed tumor tissue (figure 1d). At places, liver parenchyma showed pools of mucin containing tumor cells. Metastatic tumors showed both adenocarcinomatous and sarcomatous tissue. Immunohistochemical examination of tumor tissue was done using monoclonal anti-cytokeratin and anti-vimentin antibodies. Adenocarcinomatous tissue showed strong positivity for cytokeratin (figure 1e) and sarcomatous tissue showed vimentin antigen positivity in $60 \%$ of tumor cells (figure 1f). Tumor was diagnosed as carcinosarcoma gallbladder (CSGB) with metastases both in liver and a lymph node.

\section{Figure-1}
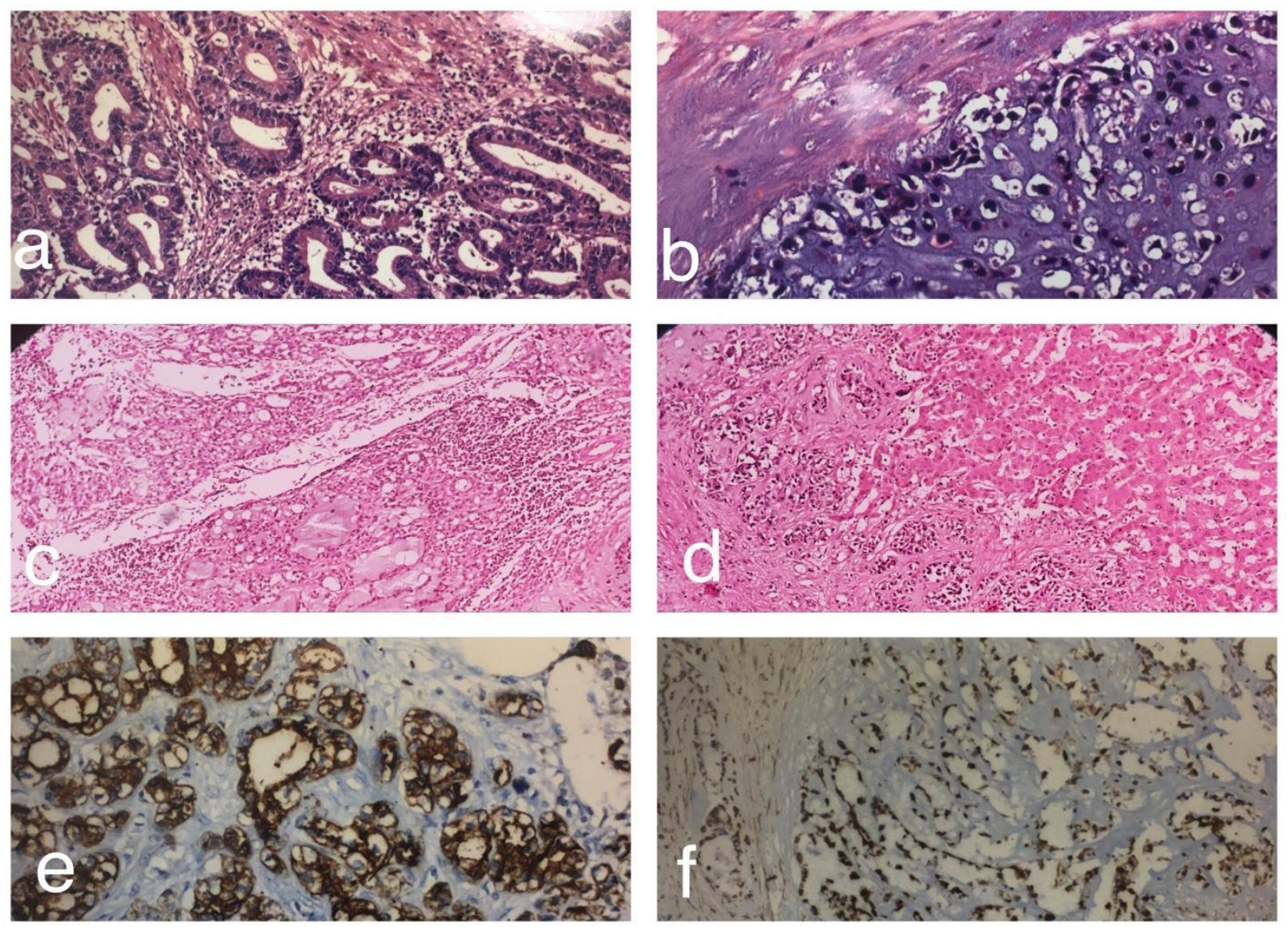

a) Shows irregular acini and papillary structures $(\mathrm{HE} \times 100)$.

b) Shows chondrosarcomatous component of tumor $(\mathrm{HE} \times 100)$.

c) Metastatic tumor lymph node $(\mathrm{HE} \times 100)$.

d) Metastatic tumor liver $(\mathrm{HE} \times 100)$.

e) Epithelial component of tumor shows strong positivity for cytokeratin antigen $(\times 100)$.

f) Mesenchymal component shows strong positivity for vimentin $(\times 100)$. 


\section{Discussion}

Most important feature of the current case was the detection of metastatic tumors both in liver and a regional lymph node. Invasion of a venule might have resulted in metastatic tumor in liver through portal vein. Spread of tumor to a regional lymph node might have occurred through invasion of an afferent lymphatic. Another interesting feature was the morphology of tumor in metastases; tumor showed carcinosarcomatous tissue both in liver and in the regional lymph node. In another study, a sarcomatous thrombus alone was detected in portal vein ${ }^{1}$. Lymphatic spread of CSGB is rare but occasionally it may occur ${ }^{2}$. Current case of CSGB was a female. Most of the cases of this tumor are females. In addition, ovariectomized estrogen-free $\mathrm{LXR}^{-/-}$mice failed to develop preneoplastic lesions ${ }^{3}$. These observations suggest role of estrogen in gallbladder carcinogenesis. Another interesting feature was the detection of multiple sludge-balls in our case. Sludge-balls are known to be the precursors of gall stones; these structures develop due to bile stasis. Role of bile stasis has also been suggested in an earlier study ${ }^{4}$.Pancreatico-biliary reflux due to maljunction may also be associated with biliary carcinogenesis. Several risk factors may be involved in gallbladder carcinogenesis, e.g. chronic inflammation by Helicobacter species or Salmonella typhi ${ }^{5,6}$. In addition, p53 gene mutations may trigger gallbladder carcinogenesis ${ }^{7}$. Role of survivin, an appotosis-inhibiting protein has been suspected in gallbladder carcinogenesis. Furthermore, increased survivin expression was observed in poorly differentiated malignant tumor when compared with well differentiated gallbladder carcinoma ${ }^{8}$. Most of the patients with CSGB die within 6 months after surgery. The patients with tumors $<5 \mathrm{~cm}$ had longer survival as compared to those with bigger tumors ${ }^{9}$. Targeted therapies using anti-angiogenic and anti HER 2/neu agents may be beneficial to CSGB patients ${ }^{7}$.

\section{Conclusion}

Carcinosarcoma is a rare malignancy of gallbladder. Exact etiopathogenesis of this tumor is not known. A 60 years old female had a gallbladder tumor. Tumor showed the features of both adenocarcinoma and chondrosarcoma. Moreover, carcinosarcomatous tissue metastasized to liver as well as to a regional lymph node. In spite of surgery, prognosis of carcinosarcoma is poor. However, longer survival may occur in a few patients.

\section{Financial support and sponsorship: Nil}

Conflicts of interest: There are no conflicts of interest.

\section{References}

1. Herrera-Goepfert R, Ortega Jde JM, Rodriguez-Martinez HA. Carcinosarcoma of the gallbladder. HistolHistopath 1987; $2: 273-275$.

2. Park SB, Kim YH, Rho HL, Chae GB, Hong SK. Primary carcinosarcoma of the gallbladder. J of Korean Surg Society 2012; $82: 54-58$.

3. Gabbi C, Kim H, Barros R, Korach-Andre M, Warner M, Gustafsson J. Estrogendependent gallbladder carcinogenesis in $\mathrm{LXR}^{-/-}$female mice. PNAS 2010; 107(33) : 14763-14768.

4. Huguet KL, Hugbes CB, Hewitt WR. Gallbladdercarcinosarcoma : A case report and literature review. J GastrointestSurg 2005; $9: 818-821$.

5. Li Y, Zhang J, Ma H. Chronic inflammation and gallbladder cancer. Cancer letters 2014; $345: 242-248$.

6. Nath G, Singh H, Shukla VK. Chronic typhoid carriage and carcinoma of the gallbladder. Eur J Cancer prev 1997; 6 : 557-559.

7. Barreto SG, Dutt A, Chaudhary A. A genetic model for gallbladder carcinogennesis and its dissemination. Annals of oncology 2014; 25 : 1086-1097. 
8. Nigam J, Chandra A, Kazmi HR, Parmar D, Singh D, Gupta V. Prognostic significance of survivin in resected gallbladder cancer. J Surg Res 2015; 194 : 57-62.

9. Zhang L, Chen Z, Fukuma M, Lee LY, Wu M. Prognostic significance of race and tumor size in carcinosarcoma of gallbladder. A meta-Analysis of 68 cases. Int J ClinExpPathol 2008; 1:75-83. 